\title{
Barriers to effective health care for patients who have smell or taste disorders
}

\author{
Stephen Ball ${ }^{1}$ | Duncan Boak ${ }^{2}$ | Joanne Dixon ${ }^{2}$ | Sean Carrie ${ }^{3}$ | Carl M. Philpott ${ }^{2,4,5}$
}

${ }^{1}$ Newcastle University Faculty of Medical Sciences, Newcastle upon Tyne, UK

${ }^{2}$ Fifth Sense, Barrow-on-Furness, UK

${ }^{3}$ Newcastle upon Tyne Hospitals NHS Foundation Trust, Newcastle upon Tyne, UK ${ }^{4}$ The Norfolk Smell \& Taste Clinic (Norfolk \& Waveney ENT Service), James Paget University Hospital, Gorleston, UK

${ }^{5}$ Norwich Medical School, University of East Anglia, Norwich, UK

\section{Correspondence}

Carl M. Philpott, Norwich Medical School, University of East Anglia, NR4 7TJ Norwich, UK.

Email: C.Philpott@uea.ac.uk

\section{Funding information}

Newcastle University Faculty of Medical Sciences Tilly Hale Award: Celebrating Excellence in Public \& Patient Engagement \& Involvement (PPE/I)

\begin{abstract}
Objectives: Smell/taste disturbances are a common but underrated, under-researched and under treated sensory loss and an independent risk factor for reduced longevity. This study aimed to characterise the experience of patients with these disorders in seeking help.

Design: The study was designed by patients together with clinicians through a dedicated workshop and conducted as a cross-sectional survey to capture experiences in public and private healthcare settings internationally.

Setting: Primary, secondary and tertiary care.

Participants: Any members of the public self-reporting a smell/taste disorder were invited to participate.

Main outcome measures: The survey captured information including experience of getting consultations and referrals to medical professionals, treatments offered, costs incurred and related problems with mental health.

Results: Of 673 participants; 510 female, 160 male, three not stated, self-reported aetiology included sinonasal disease (24\%), idiopathic (24\%) and post-viral olfactory dysfunction (22\%); true gustatory disorders were typically rare. Failure of medical professionals to recognise the problem was a key concern - $64 \%, 76 \%$ and $47 \%$ of GPs, ENT specialists and Neurologists acknowledged, respectively. Other issues included repeated ineffective treatments, difficulties getting referrals to secondary/ tertiary care, mental health problems $(60 \%)$ and a mean personal cost of $£ 421$ to seeking advice and treatment. Whilst the participants were self-selecting, however, they do represent those who are seeking help and intervention for their disorders.

Conclusion: There is an unmet need for these patients in accessing health care including a clear need to improve education of and engagement with the medical profession in Otorhinolaryngology, General Practice and other specialties, in order to remove the current barriers they face.
\end{abstract}




\section{1 | INTRODUCTION}

\section{1 | Background and rationale}

Smell is the forgotten sense; even when facing a problem with their sense of smell, patients often struggle to get recognition, let alone diagnosis or treatment from healthcare professionals. Based on comparative data from the Royal National Institutes for the Blind and the Deaf, olfactory disorders are as common as profound hearing loss and blindness affecting an estimated $5 \%-20 \%$ of the population. ${ }^{1}$ Common causes of olfactory disorders include chronic rhinosinusitis, post-viral olfactory loss and post-traumatic olfactory loss ${ }^{2}$ as well as it being present in the majority of cases of Parkinson's disease and common in Alzheimer's disease. ${ }^{3}$ We have also witnessed the rise of sudden onset anosmia as a marker of COVID-19 infection caused by the SARS-CoV-2 virus. ${ }^{4-11}$ It remains to be seen how many new cases of lasting olfactory loss will arise from those afflicted by the pandemic, but it is possible that over 6 million people globally now have symptoms that last beyond 4 weeks based on WHO infection rates.

Recent population studies have now identified anosmia as an independent risk factor for shortened longevity, even after controlling for dementia and cardiovascular disease. ${ }^{12-15}$ It is not clear why this is so but may suggest that the olfactory system acts as a barometer of environmental impact on the central nervous system as a whole. As this phenomenon has been observed in several countries it clearly demonstrates that olfactory disorders deserve to receive greater attention than they currently do.

Taste is often thought to be lost by those affected by olfactory disorders due to the misperception of retronasal olfaction as a "taste" sensation. In reality only a small percentage of people reporting a problem with their sense of smell or taste experience a true gustatory disorder, but due to this common misperception alongside the need to be representative of all patients with chemosensory disorders, it is always important to encapsulate both senses within any work of this kind.

Fifth Sense, the UK charity for people affected by smell and taste disorders, was founded in 2012 when authors DB and CP met and agreed on the need for patient advocacy to tackle the unmet needs of patients affected by olfactory disorders. Since then, with the help of a growing membership, we have been able to characterise the significant impact of olfactory disorders on those affected ${ }^{16,17}$ and we have also become aware of the frustrations many members in their attempts to seek medical help and getting their sensory loss taken seriously. ${ }^{17-19}$ In 2019, Fifth Sense was awarded a National Lottery Grant for $£ 238815$ to enable it to develop and grow its work, including the establishment of a network of patient support hubs.

\section{2 | Objectives}

Following on from the above, this study aimed to characterise the details of the difficulties faced by patients with olfactory and

\section{Keypoints}

- Smell/taste disorder patients have difficulty getting their disorder recognised.

- Key problems are a lack of onward referral and repeated ineffective treatments.

- Neurologists are least likely to acknowledge their disorders.

- Mental health problems secondary to their disorder are very common.

- Patient engagement in research priorities is critical and being addressed through a Priority Setting Partnership.

gustatory disorders in accessing health care as a patient and public co-production. ${ }^{20}$

\section{MATERIALS AND METHODS}

\section{1 | Study design}

The study was designed as a cross-sectional survey of the experience of people affected by olfactory disorders in accessing medical care. A survey questionnaire was developed using a focus group meeting of the public, patients and clinicians (Figures 1 and 2). The survey was then set live online and ran for 16 weeks. It was promoted via social media internationally. As the survey was anonymous and considered to be service evaluation, there was no ethical approval sought in line with the Health Regulation Authority guidance: http:// www.hra-decisiontools.org.uk/research/docs/DefiningResearchTable_Oct2017-1.pdf.

\section{2 | Setting}

The survey was open to anyone globally with access to the world wide web and declaring themselves an affected individual and was promoted through social media channels including the Fifth Sense website, and its Facebook and Twitter accounts. The survey was launched via the website with an introduction found in Appendix 1.

\section{3 | Participants}

\subsection{1 | Eligibility criteria}

All members of the public self-reporting a loss or disturbance of olfaction and/or gustation were entitled to participate in the survey. 


\subsubsection{Sources and methods of selection of participants}

Survey participants were able to access the survey themselves free of charge via the web-based platform SurveyMonkey. Participants were self-selecting and could participate from any country internationally.

\section{4 | Data sources/management and variables}

The survey asked for basic demographics including age and sex. Participants were asked to declare the underlying cause for their smell loss. Further questions explored participants use of medical services, costs borne in doing so and any resistance encountered. See Appendix 1 for details.

\section{$2.5 \mid$ Bias}

We aimed to reduce bias in responses by making the survey widely available but inevitably, those who are not online or have access to the aforementioned social media would not have seen this opportunity. Although the survey was initiated in the UK and Fifth Sense membership is predominantly UK based, the international availability aimed to derive a broader healthcare view across other healthcare systems.

\subsection{Study size and statistical methods}

As this was an exploratory study, no sample size was set. Due to the nature of the study, descriptive statistics only have been utilised in reporting the survey data.

\section{RESULTS}

\section{1 | Participants}

A total of 673 participants recorded information on the survey during the study period. Not all 673 participants responded to every question, so percentages below are expressed with the total number of responses as the denominator. For reference, there are currently 3000 people registered as members of Fifth Sense.

\section{2 | Descriptive data}

Of the 673 participants, 510 were female and 160 were male; three preferred not to state their gender. The age of participants ranged from 10 to 88, with a mean age of 56 and a mode age of 63. The geographic distribution of participants can be seen in Figure 3 with

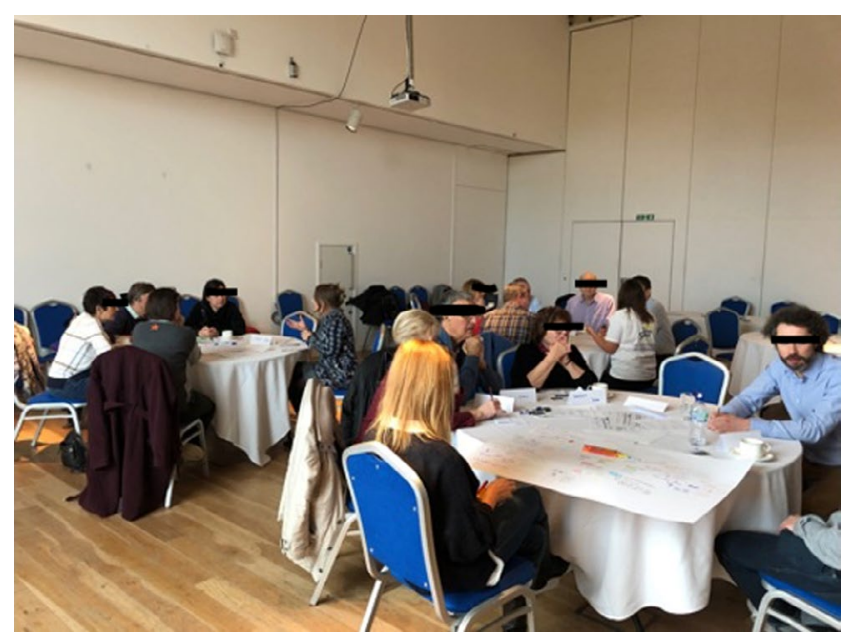

FIGURE 1 Workshop in progress-Group discussions between participants, Fifth sense members, clinicians, researchers and artists to expand on the themes of the day-"mapping the patient journey \& its challenges"

469 (70\%) reporting their location as being in the UK. The aetiology reported for participants can be seen in Figure 4 with 28\% reporting chronic rhinosinusitis, allergic rhinitis or Aspirin/Non-Steroidal Exacerbated Respiratory Disease (A/NERD) and 25\% reporting postviral olfactory loss (PVOL). The range of duration of reported olfactory disorders was 1 month to 67 years with a mean of 13 years and a mode of 2 years.

\subsection{Main results}

\subsubsection{Recognition of the olfactory disorder as a significant problem}

Getting recognition from doctors that their condition is a significant problem for them was challenging for some participants, with $64 \%$ reporting that their GP positively recognised their disorder and $76 \%$ reporting recognition by an otorhinolaryngologist; for those who had seen a neurologist, only $47 \%$ reported that they felt their disorder had been recognised and for those seeking a private specialist opinion, 66\% (Table 1a-c).

\subsection{2 | Prescription of treatment}

In primary care, 195 respondents (40\%) reported receiving a prescription related to their olfactory disorder. In secondary care, respondents reported receiving a prescription from $54 \%$ of otorhinolaryngologists and $10 \%$ of neurologists, respectively. For those who sought private consultations, $46 \%$ reported receiving a prescription. Repeated treatments were reported from 31\% of GPs to $37 \%$ of otorhinolaryngologists. In terms of effectiveness of the treatment, $8 \%$ of GP prescriptions, $23 \%$ of ENT prescriptions, $2 \%$ 


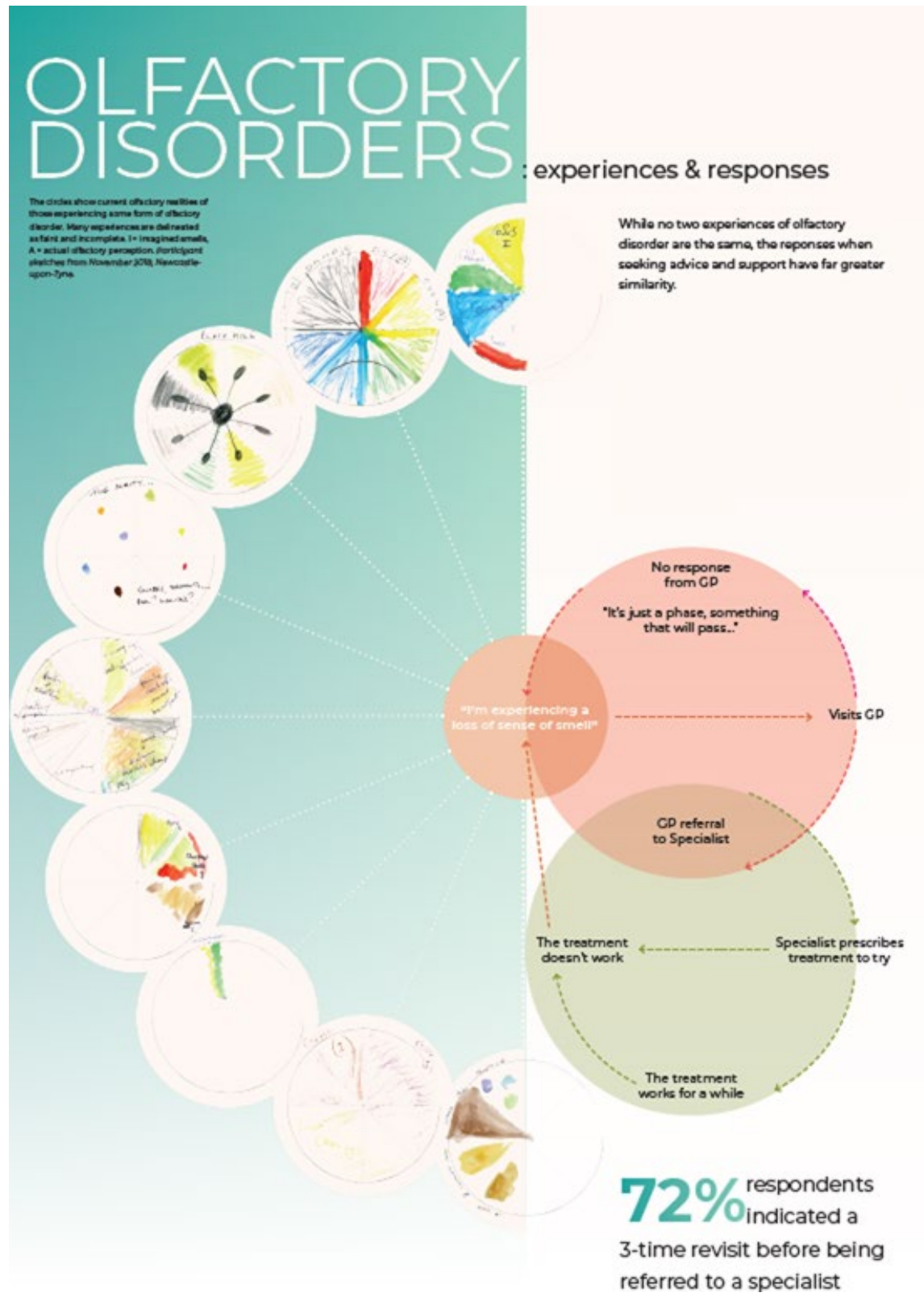

FIGURE 2 "Customer journey"workshop activity

of neurology prescriptions and $20 \%$ of private prescriptions were deemed by the patients to have helped improve their sensory deficit.

\subsection{3 | Useful information and advice}

In primary care, only $7 \%$ felt that they received useful information and advice, with a rise to $33 \%$ for ENT and $13 \%$ in neurology in secondary care and in the private sector only $28 \%$.

\subsection{4 | Healthcare consultations}

The range of reported GP consultations for respondents was 0-150 with a mean of 5.8 and a mode of 1 . In Otorhinolaryngology, the range was $0-75$ with a mean of 4.6 and a mode of 1 . For Neurology, this was much lower with a range of $0-54$ and a mean of 0.9 , and similarly, in private health care, the range was 0-50 with a mean of 1.7. Seventy-one per cent of respondents reported being able to get a referral to Otorhinolaryngology and of these $34 \%$ were given a choice of location but only $20 \%$ a choice of specialist. Information from the Fifth Sense website informed $29 \%$ to guide their choice of referral centre with $54 \%$ having to request the referral themselves and $59 \%$ stating they felt their case was recognised as needing a referral. Only $4 \%$ of respondents reported having their case declined by their local Clinical Commissioning Group but $40 \%$ felt that Fifth Sense information had helped the process of getting medical advice.

\subsection{5 | Travel and cost of healthcare appointments}

Respondents were asked to estimate how far they had travelled in miles to seek information or treatment for their disorder and reported a range of 0 to 15250 miles with a mean of 200 miles and a 
FIGURE 3 Geographic distribution of survey respondents
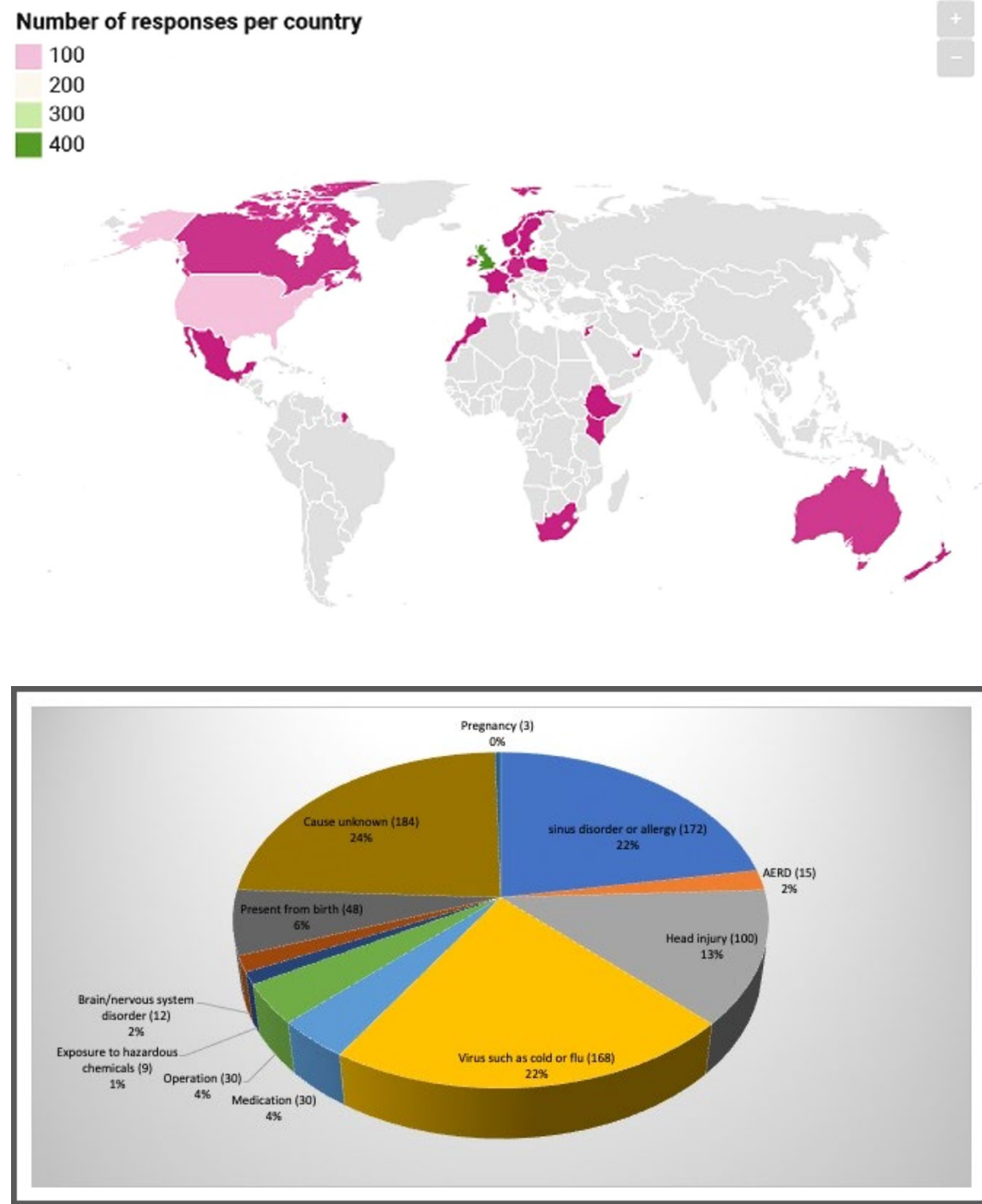

FIGURE 4 Aetiology of respondents

median of 30 miles. The personal cost of doing so showed a range of $£ 0-41100$ (highest figure in USA) with a mean of $£ 421$ and a median of $£ 50$. When analysed further by country, the USA has the highest mean cost per respondent at $£ 2277$, followed by Australia, Canada, United Kingdom and New Zealand (Table 2).

\subsection{6 | Improvement and treatment impact}

Only 138 respondents reported an improvement of their disorder with $89(17 \%)$ saying they felt as if this was the result of medical advice and/or treatment and 59 (11\%) who felt that it was in response to smell training.

\subsection{7 | Quality of life including mental health}

All but 14 respondents reported an impact on their quality of life with $60 \%$ reporting either anxiety and or depression as a consequence of their sensory loss. Specific treatments reported included 102 taking GP-prescribed antidepressants/sedatives/anxiolytics (15\%), 42 taking over the counter remedies (6\%), 73 receiving counselling (11\%) and other alternative therapies used included acupuncture, marijuana use and meditation (4\%).

\subsection{8 | Overall patient perspective}

An open comments section was included to supplement the quantitative data that provided some important insights from our participants' perspectives. The quotations were chosen by our patient co-authors as representative of the typical experiences.

1. It is not really taken seriously. The attitude is almost "Well, at least you are not deaf or blind." The effect on my daily life is not recognised.

2. I am low in mood. I hate eating and don't feel hungry. It affects my job and makes me feel unsafe from fire and gas leakages. 
TABLE 1A Survey responses (part 1)

\begin{tabular}{|c|c|c|}
\hline \multirow[b]{2}{*}{ Question } & \multirow{2}{*}{$\frac{\text { Yes }}{n(\%)}$} & \multirow{2}{*}{$\frac{\text { No }}{n}$} \\
\hline & & \\
\hline \multicolumn{3}{|c|}{ Have you been seen by a } \\
\hline GP? & $507(95)$ & 27 \\
\hline ENT specialist? & $444(87)$ & 68 \\
\hline Neurologist? & $112(34)$ & 221 \\
\hline Private provider? & $130(40)$ & 199 \\
\hline \multicolumn{3}{|c|}{ Have they recognised your smell/taste disorder is a problem to you? } \\
\hline GP & $319(64)$ & 178 \\
\hline ENT specialist & $304(75)$ & 104 \\
\hline Neurologist & $58(47)$ & 66 \\
\hline Private provider & $99(66)$ & 50 \\
\hline \multicolumn{3}{|c|}{ Have you been prescribed any treatment? } \\
\hline GP & $195(40)$ & 293 \\
\hline ENT specialist & $238(54)$ & 199 \\
\hline Neurologist & $11(9)$ & 114 \\
\hline Private provider & $69(47)$ & 78 \\
\hline \multicolumn{3}{|c|}{$\begin{array}{l}\text { Have they provided you with any useful information or advice about } \\
\text { your condition? }\end{array}$} \\
\hline GP & $35(7)$ & 456 \\
\hline ENT specialist & $149(33)$ & 298 \\
\hline Neurologist & $17(13)$ & 111 \\
\hline Private provider & $41(28)$ & 107 \\
\hline \multicolumn{3}{|c|}{$\begin{array}{l}\text { Have you been prescribed the same treatment by them on more } \\
\text { than one occasion? }\end{array}$} \\
\hline GP & $123(31)$ & 269 \\
\hline ENT specialist & $131(37)$ & 223 \\
\hline Neurologist & $2(2)$ & 85 \\
\hline Private provider & $34(28)$ & 86 \\
\hline \multicolumn{3}{|c|}{$\begin{array}{l}\text { Has any treatment prescribed by them improved your sense of } \\
\text { smell/taste? }\end{array}$} \\
\hline GP & $30(8)$ & 349 \\
\hline ENT specialist & $81(22)$ & 270 \\
\hline Neurologist & $2(2)$ & 90 \\
\hline Private provider & $25(20)$ & 99 \\
\hline
\end{tabular}

3. I feel that even ENT specialists do not see this problem which truly affects your quality of life as even a problem.

4. Feel like it's minimized by people and professionals who think it must be nice not to smell kids' dirty nappies or that you're only missing out on smelling flowers and cookies in the oven. It is a real issue - gas hob, smoke, taste diminishes, lack of shared experience with family, and memories compromised.

5. Following treatment, I am able to smell again much of the time. It is so wonderful to be able to smell the ocean, to smell coffee brewing, to smell bacon or onions cooking. I can smell my husband's skin, or the soap he last used. I can smell the soap I use in the shower, which never ceases to amaze me. I can smell whether fruit is ripe or not. This is all incredibly wonderful, it adds such a
TABLE 1B Survey responses (part 2)

\begin{tabular}{|c|c|c|}
\hline Question & $\begin{array}{l}\text { Yes } \\
\text { n (\%) }\end{array}$ & No \\
\hline $\begin{array}{l}\text { Have you been referred to an ENT Specialist } \\
\text { by your GP/Neurologist? }\end{array}$ & $389(71)$ & 158 \\
\hline Were you given a choice of location? & $148(34)$ & 284 \\
\hline Were you given a choice of Specialist? & $87(20)$ & 348 \\
\hline $\begin{array}{l}\text { Did you use information obtained from Fifth } \\
\text { Sense? }\end{array}$ & $134(29)$ & 330 \\
\hline Did you request a referral? & $265(54)$ & 227 \\
\hline Were you offered a referral? & $251(53)$ & 225 \\
\hline $\begin{array}{l}\text { Was your case recognised as needing a } \\
\text { referral? }\end{array}$ & $274(60)$ & 185 \\
\hline $\begin{array}{l}\text { Was your case declined by the local Clinical } \\
\text { Commissioning Group (CCG) so your GP was } \\
\text { unable to help you? }\end{array}$ & $12(4)$ & 294 \\
\hline $\begin{array}{l}\text { Has information provided by Fifth Sense } \\
\text { helped you in your efforts to get medical } \\
\text { advice? }\end{array}$ & $223(40)$ & 339 \\
\hline $\begin{array}{l}\text { Do you consider that your smell/taste } \\
\text { disorder has affected your quality of life? }\end{array}$ & $548(98)$ & 14 \\
\hline $\begin{array}{l}\text { Have you suffered from anxiety or depression } \\
\text { as a result of your smell disorder? }\end{array}$ & $340(61)$ & 221 \\
\hline \multicolumn{3}{|l|}{ If yes to anxiety or depression, have you? } \\
\hline $\begin{array}{l}\text { Taken any medication prescribed by your } \\
\text { GP? (eg antidepressants, sedatives, } \\
\text { anxiolytics) }\end{array}$ & $102(30)$ & 238 \\
\hline Taken an over-the-counter medicine? & $42(12)$ & 298 \\
\hline Taken an alternative medicine remedy? & $75(22)$ & 265 \\
\hline Received counselling? & $73(21)$ & 267 \\
\hline $\begin{array}{l}\text { Do you think your ability to smell/taste } \\
\text { has improved since you first encountered } \\
\text { problems with it? }\end{array}$ & $138(27)$ & 376 \\
\hline $\begin{array}{l}\text { Do you feel that this is as a result of medical } \\
\text { advice and/or treatment? }\end{array}$ & $89(20)$ & 353 \\
\hline $\begin{array}{l}\text { Do you feel that this is the result of a } \\
\text { complementary therapy such as smell } \\
\text { training? }\end{array}$ & $59(14)$ & 354 \\
\hline
\end{tabular}

TABLE 1C Survey responses (part 3)

\begin{tabular}{lcc} 
& Mean & Range \\
How many appointments have you had in total with? & \\
GPs & 5.6 & $0-150$ \\
ENT specialist & 4.6 & $0-75$ \\
Neurologist & 0.9 & $0-54$ \\
Private provider & 1.6 & $0-50$ \\
\hline
\end{tabular}

richness to your life. Not to mention: I can smell gas, if the burner on the stove didn't turn on correctly, or paint, if a hallway is newly painted. I can smell if milk has gone sour. If I can smell these things I can protect myself from them better. 
TABLE 2 Mean healthcare cost per country, where five or more responses received

\begin{tabular}{llc}
\hline & Average cost (GBP) & $\begin{array}{c}\text { Number of } \\
\text { responses }\end{array}$ \\
\hline The United States & 2277 & 121 \\
\hline Australia & 1491 & 23 \\
\hline Canada & 407 & 13 \\
\hline UK & 375 & 477 \\
\hline New Zealand & 190 & 5 \\
\hline
\end{tabular}

\section{4 | DISCUSSION}

\section{1 | Key results}

Our study serves to illustrate a number of significant issues faced by patients with chemosensory disorders. Firstly, a lack of recognition in the wider medical profession but still with 1 in 4 ENT specialists failing to convince their patients that they appreciated the impact of their olfactory disorder; this was even more noticeable in over half of neurologists encountered. In fact, it is evident that the experience of this patient group with neurologists was largely disappointing. Secondly, knowledge of appropriate treatments is lacking thus leading to no treatment or to repeated ineffective treatments being applied. This was further exacerbated by participants expressing little satisfaction with the usefulness of the advice given. Thirdly, accessing a specialist consultation was a challenge with 1 in 4 reporting difficulty in getting a referral. Due to the paucity of specialists dedicated to chemosensory disorders, respondents reported significant journeys and costs associated with that. Finally, mental health aspects of being affected by chemosensory disorders have been clearly highlighted and 15\% reported taking prescribed medication for this, therefore, also emphasising an additional healthcare burden.

\subsection{Limitations}

The survey will not have been seen by those who are not online or do not have access to the aforementioned social media. This is likely to have disproportionately affect the older generations. Due to the origin of the survey in the UK and with Fifth Sense being a UK-based charity, over two thirds of the respondents reflect their experience with the National Health Service setting in the UK. It is also possible that an unknown number of patients may have had a good response to treatment, but these cases will not be apparent if they are not Fifth Sense members or have chosen not to respond to the survey because they were happy with the outcome of their treatment. It may also be that the treatments applied were reasonable, but nonetheless proved ineffective in resolving or improving the olfactory disorder. The charity membership and survey respondents will also tend to be more likely to be those who have persistent symptoms and thus are more difficult to treat. That said, respondents are reflective of those in need and seeking care and attention and have been shown in our previous work to use NHS resources in other ways if their sensory loss(es) are not addressed. ${ }^{16}$ The survey also captured a retrospective perspective on those who had experienced difficulties with accessing healthcare.

The travel and cost issues demonstrated a significant spread of data; this may however reflect the small number of specialist centres seeing these patients and thus the distances and costs they face having to travel to them; the authors know of patients willing to travel to another continent for help and advice, even in countries with established health services free at the point of access.

Although the survey is based on self-reporting and no psychophysical testing has been performed, this obviously would not reflect the nature of the core problem facing these patients; they are unable to access a clinician and smell/taste testing in the first place. For any children participants, the responses will reflect the views of the parents/guardians rather than the child.

\section{3 | Interpretation}

The demographics and aetiology of study participants were in keeping with the typical female predominance seen in other studies and with sinonasal disease and post-viral olfactory loss as leading causes. ${ }^{21-24}$ The study also underlines the mental health impact of previous studies in those with olfactory disorders. ${ }^{16,17,21}$ However, this study makes a clear reflection on the paucity of services provided to this patient group and shows that the relatively poor engagement by the medical profession has changed little in nearly two decades. ${ }^{25}$ Our data would suggest this is clearly an issue in the UK healthcare setting, but international responses also suggest this is potentially a global issue with little emphasis placed on either the importance of these senses in everyday life or the consequences of losing them.

\subsection{Generalisability}

There is an unmet need for patients with olfactory disorders in accessing healthcare including engagement from the medical profession and signposting to appropriate information and treatment options. ${ }^{26}$ It remains to be seen as to whether the current wave of COVID-19-related smell loss as a result of the global pandemic will give rise to an increase in patients presenting with post-viral olfactory loss but with an estimated rate of anosmia globally of $5 \%$ and hyposmia up to $20 \%$, these disorders are common and engagement from the medical profession is not matching this. This underlines the raison d'être of Fifth Sense which amongst its strategic aims is the need to improve education of the role of these senses in everyday life as well as providing support for those affected by these disorders. To move this forward, Fifth Sense plans to work with the medical profession to not only provide patient support, but also to work with the wider body of stakeholders that need to be engaged in improving the current situation faced by these patients 
in accessing suitable care, including appropriate psychological support. As part of this initiative, Fifth Sense is leading the James Lind Alliance Priority Setting Partnership to determine what should be the top ten research priorities for those with smell and taste disorders https://www.jla.nihr.ac.uk/priority-setting-partnerships/ smell-and-taste-disorders/.

\section{REPORTING GUIDELINES}

This study has been reported in line with the Strobe guidelines (see Appendix 2).

\section{DATA AVAILABILITY STATEMENT}

Data can be made available on request to s.l.ball@ncl.ac.uk.

\section{ORCID}

Carl M. Philpott iD https://orcid.org/0000-0002-1125-3236

\section{REFERENCES}

1. Landis BN, Konnerth CG, Hummel T. A study on the frequency of olfactory dysfunction. Laryngoscope. 2004;114(10):1764-1769.

2. Damm M, Temmel A, Welge-Lüssen A, et al. Olfactory dysfunctions. Epidemiology and therapy in Germany, Austria and Switzerland. HNO. 2004;52(2):112-120.

3. DeVere R. Disorders of taste and smell. Continuum. 2017;23(2, Selected Topics in Outpatient Neurology):421-446.

4. Vaira LA, Salzano G, Deiana G, De Riu G. Anosmia and Ageusia: common findings in COVID-19 patients. Laryngoscope. 2020;130(7):1787.

5. Yan CH, Faraji F, Prajapati DP, Boone CE, DeConde AS. Association of chemosensory dysfunction and Covid-19 in patients presenting with influenza-like symptoms. Int Forum Allergy Rhinol. 2020;10(7):806-813.

6. Lechien JR, Chiesa-Estomba CM, De Siati DR, et al. Olfactory and gustatory dysfunctions as a clinical presentation of mildto-moderate forms of the coronavirus disease (COVID-19): a multicenter European study. Eur Arch Otorhinolaryngol. 2020;277(8):2251-2261.

7. Moein ST, Hashemian SMR, Mansourafshar B, Khorram-Tousi A, Tabarsi P, Doty RL. Smell dysfunction: a biomarker for COVID-19. Int Forum Allergy Rhinol. 2020;10(8):944-950.

8. Lechner M, Chandrasekharan D, Jumani K, et al. Anosmia as a presenting symptom of SARS-CoV-2 infection in healthcare workers - a systematic review of the literature, case series, and recommendations for clinical assessment and management. Rhinology. 2020;58(4):394-399.

9. Parma V, Ohla K, Veldhuizen MG, et al. More than smell - COVID-19 is associated with severe impairment of smell, taste, and chemesthesis. Chem Senses. 2020;45(7):609-622.

10. Menni C, Valdes AM, Freidin MB, et al. Real-time tracking of self-reported symptoms to predict potential COVID-19. Nat Med. 2020;26(7):1037-1040.
11. Lechner M, Liu J, Counsell N, et al. Course of symptoms of loss of sense of smell over time in one thousand forty-one healthcare workers during the Covid-19 pandemic: our experience. Clin Otolaryngol. 2020;46(2):451-457.

12. Pinto JM, Wroblewski KE, Kern DW, Schumm LP, McClintock MK. Olfactory dysfunction predicts 5-year mortality in older adults. PLoS One. 2014;9(10):e107541.

13. Laudisio A, Navarini L, Margiotta DPE, et al. The association of olfactory dysfunction, frailty, and mortality is mediated by inflammation: results from the InCHIANTI study. J Immunol Res. 2019;2019:1-8.

14. Liu B, Luo Z, Pinto JM, et al. Relationship between poor olfaction and mortality among community-dwelling older adults: a cohort study. Ann Intern Med. 2019;170(10):673-681.

15. Devanand DP, Lee S, Manly J, et al. Olfactory identification deficits and increased mortality in the community. Ann Neurol. 2015;78(3):401-411.

16. Philpott CM, Boak D. The impact of olfactory disorders in the United Kingdom. Chem Senses. 2014;39(8):711-718.

17. Erskine SE, Philpott CM. An unmet need: patients with smell and taste disorders. Clin Otolaryngol. 2020;45(2):197-203.

18. Erskine SE, Notley C, Wilson AM, Philpott CM. Managing chronic rhinosinusitis and respiratory disease: a qualitative study of triggers and interactions. J Asthma. 2015;52(6):600-605.

19. Erskine SE, Verkerk MM, Notley C, Williamson IG, Philpott CM. Chronic rhinosinusitis: patient experiences of primary and secondary care - a qualitative study. Clin Otolaryngol. 2016;41(1):8-14.

20. Hickey G, Richards T, Sheehy J. Co-production from proposal to paper. Nature. 2018;562(7725):29-31.

21. Keller A, Malaspina D. Hidden consequences of olfactory dysfunction: a patient report series. BMC Ear Nose Throat Disord. 2013;13(1):8.

22. Langstaff L, Pradhan N, Clark A, et al. Validation of the olfactory disorders questionnaire for English-speaking patients with olfactory disorders. Clin Otolaryngol. 2019;44(5):715-728.

23. Hummel T, Whitcroft KL, Andrews $P$, et al. Position paper on olfactory dysfunction. Rhinol Suppl. 2017;54(26):1-30.

24. Philpott CM. Smell and taste disorders in the UK: first experience with a specialised small and taste outpatient clinic. Ann R Coll Surg Engl. 2014;96:156-159.

25. McNeill E, Ramakrishnan Y, Carrie S. Diagnosis and management of olfactory disorders: survey of UK-based consultants and literature review. J Laryngol Otol. 2007;121(8):713-720.

26. Addison AB, Wong B, Ahmed T, et al. Clinical Olfactory Working Group consensus statement on the treatment of post infectious olfactory dysfunction. J Allergy Clin Immunol. 2021;147(5):1704-1719.

How to cite this article: Ball S, Boak D, Dixon J, Carrie S, Philpott CM. Barriers to effective health care for patients who have smell or taste disorders. Clin Otolaryngol. 2021;00:1-10. https://doi.org/10.1111/coa.13818 


\section{APPENDIX 1}

\section{Introductory statement provided to participants}

Fifth Sense is launching a survey to capture patients' experiences of navigating the healthcare system. We know that so many of you face real challenges in getting support, advice or treatment from your doctors, although there are success stories too. The survey has been designed to capture data that will highlight both these challenges and successes as part of our ongoing efforts to improve awareness amongst the medical profession and improve patient experience.

We believe that this is the first piece of research to focus specifically on this issue and we're very proud to be part of a multidisciplinary project team. Supported by a grant from Newcastle Medical School, Fifth Sense have partnered with Mr Sean Carrie and Stephen Ball from Newcastle Freeman Hospital and Newcastle University and Olfactory Mapmaker Kate McLean and her colleague Rachel Hancock. An event in Newcastle in November 2018 brought together Fifth Sense and Voice North members to share experiences and help with the design of the survey. Kate and Rachel made drawings that captured the issues discussed and asked guests to complete "smell wheels" to visually represent their own smell experiences.

The results of the survey will be used to:

1. Inform Fifth Sense's ongoing efforts to raise awareness of smell and taste disorders amongst the medical profession and the need for widespread education/training for healthcare professionals

2. Help us develop information aimed at both patients and healthcare professionals to help ensure that patients have the best possible experience when seeking medical advice

3. Help future efforts to improve the patient journey through the healthcare system for people with a smell/taste disorder

4. Provide data to support applications future research studies and projects

5. Kate and Rachel are designing a poster to accompany the results which will visually represent some of the challenges faced by patients

6. The results will be published in an appropriate medical journal and on the Fifth Sense website.

The survey is completely anonymous and should take no longer than 10-15 minutes to complete. It is based on the UK healthcare system, but it should still be relevant if you are based in another country. We would like contributions from people outside the UK as this data may help to show that this is a global issue. We'd also like to hear from parents of a child with a smell/taste disorder who have sought medical advice as it's important that your voices are heard too.

\section{APPENDIX 2}

\section{STROBE Statement-checklist of items that should be included in reports of observational studies}

\begin{tabular}{|c|c|c|}
\hline & Item No & Recommendation \\
\hline \multirow[t]{2}{*}{ Title and abstract } & \multirow[t]{2}{*}{1} & (a) Indicate the study's design with a commonly used term in the title or the abstract \\
\hline & & $\begin{array}{l}\text { (b) Provide in the abstract an informative and balanced summary of what was done and what was } \\
\text { found }\end{array}$ \\
\hline \multicolumn{3}{|l|}{ Introduction } \\
\hline $\begin{array}{l}\text { Background/ } \\
\text { rationale }\end{array}$ & 2 & Explain the scientific background and rationale for the investigation being reported \\
\hline Objectives & 3 & State specific objectives, including any prespecified hypotheses \\
\hline \multicolumn{3}{|l|}{ Methods } \\
\hline Study design & 4 & Present key elements of study design early in the paper \\
\hline Setting & 5 & $\begin{array}{l}\text { Describe the setting, locations, and relevant dates, including periods of recruitment, exposure, } \\
\text { follow-up, and data collection }\end{array}$ \\
\hline \multirow[t]{6}{*}{ Participants } & \multirow[t]{6}{*}{6} & $\begin{array}{l}\text { (a) Cohort study-Give the eligibility criteria, and the sources and methods of selection of } \\
\text { participants. Describe methods of follow-up }\end{array}$ \\
\hline & & Case-control study-Give the eligibility criteria, and the sources and methods of case \\
\hline & & ascertainment and control selection. Give the rationale for the choice of cases and controls \\
\hline & & $\begin{array}{l}\text { Cross-sectional study-Give the eligibility criteria, and the sources and methods of selection of } \\
\text { participants }\end{array}$ \\
\hline & & $\begin{array}{l}\text { (b) Cohort study-For matched studies, give matching criteria and number of exposed and } \\
\text { unexposed }\end{array}$ \\
\hline & & Case-control study-For matched studies, give matching criteria and the number of controls per case \\
\hline
\end{tabular}

(b) Cohort study-For matched studies, give matching criteria and number of exposed and

Case-control study-For matched studies, give matching criteria and the number of controls per case 


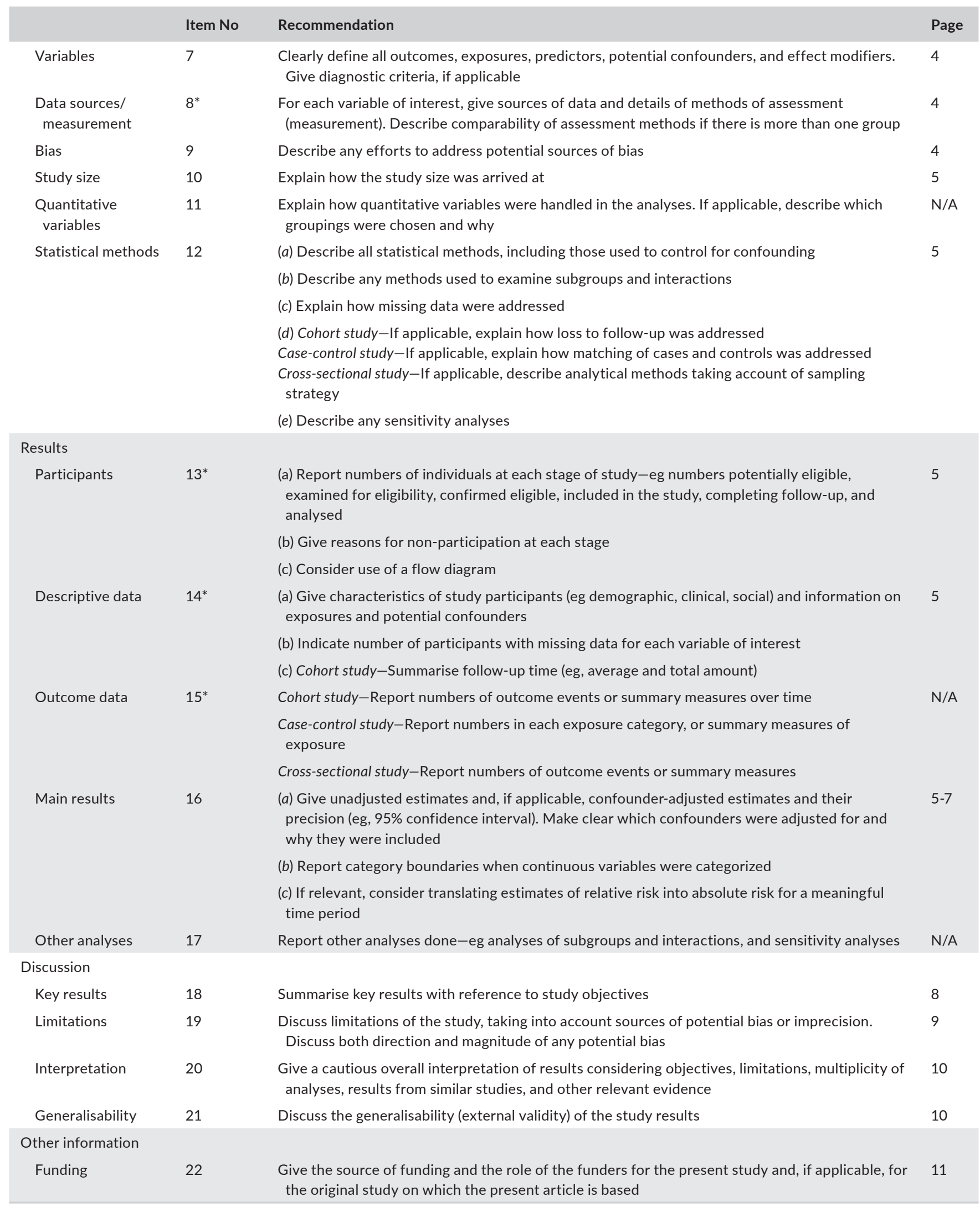

